\title{
0 Papel da Cobertura Vegetal nos Ambientes Urbanos e Sua Influência na Qualidade de Vida nas Cidades
}

\author{
Taíse Ernestina Prestes Duarte ${ }^{1}$ \\ Fabio Henrique Soares Angeoletto ${ }^{2}$ \\ Jeater Waldemar Maciel Correa Santos ${ }^{3}$ \\ Deleon da Silva Leandro \\ João Fernando Copetti Bohrer ${ }^{5}$ \\ Marcelo Caetano Vacchiano 6 \\ Leandro Bernardo Leite ${ }^{7}$
}

http://dx.doi.org/10.21527/2237-6453.2017.40.175-203

\section{Resumo}

0 presente estudo teve como objetivo compreender os benefícios da cobertura vegetal para a qualidade de vida urbana, estabelecendo como esta qualidade é mensurada e refletindo sobre o manuseio da cobertura vegetal nativa no processo de formação e expansão dos espaços urbanos. A pesquisa buscou ainda abordar aspectos relativos à cobertura vegetal urbana em Rondonópolis - MT, um município de médio porte, que vivencia um processo de crescimento acelerado desde a década de 70 do século 20. Para compreender a influência da cobertura vegetal na qualidade de vida nas cidades e sua função nos ambientes urbanos, o presente estudo propôs uma reflexão crítica sobre o papel da cobertura vegetal nos ecossistemas urbanos, por meio de uma revisão narrativa com base em artigos científicos, livros, teses e dissertações sobre a temática. A presente revisão narrativa abordou os ecossistemas urbanos diante do intenso crescimento urbano e a consequente deterioração da

1 Mestre em Geografia pela Universidade Federal de Mato Grosso (taisepduarte@hotmail.com)

2 Doutor em Ecologia pela Universidade Autônoma de Madrid. Professor permanente do Programa de Pós-Graduação em Geografia da UFMT, campus de Rondonópolis (fabio_angeoletto@yahoo.es)

3 Doutor em Geografia pela USP. Professor permanente do Programa de Pós-Graduação em Geografia da UFMT, campus de Rondonópolis (jeater@ufmt.br)

4 Acadêmico do Mestrado em Geografia da UFMT, campus de Rondonópolis (deleon_roo@hotmail.com) 5 Acadêmico do Mestrado em Geografia da UFMT, campus de Rondonópolis (jf.bohrer@hotmail.com)

6 Acadêmico do Mestrado em Geografia da UFMT, campus de Rondonópolis (marcelo.vacchiano@hotmail.com)

7 Acadêmico do Mestrado em Geografia da UFMT, ampus de Rondonópolis (leandronago@hotmail.com) 
qualidade ambiental proporcionada à população urbana. Desta forma, o trabalho permitiu uma melhor compreensão da influência da cobertura vegetal na qualidade de vida nas cidades, estabelecendo que a cobertura vegetal exerce funções ecossistêmicas específicas, que em boa parte das vezes são completamente ignoradas pelo planejamento urbano. Em complemento, a análise de estudos locais referentes à cobertura vegetal em Rondonópolis permitiu compreender como este município, em franca expansão, organiza e mantém a cobertura vegetal em seu espaço urbano.

Palavras-chave: Ecossistemas urbanos. Arborização urbana. Qualidade ambiental.

\title{
THE ROLE OF VEGETATION IN URBAN ENVIRONMENTS AND THEIR INFLUENCE ON QUALITY OF LIFE IN CITIES
}

\begin{abstract}
This study aimed to understand the benefits of the vegetation cover for the quality of urban life, setting as this quality is measured and, reflecting on the handling of the native vegetation in the process of formation and expansion of urban spaces. This study also sought, address aspects of urban vegetation in Rondonópolis - MT, while a medium-sized municipality, which experiences a process of accelerated growth from the 1970s to understand the influence of vegetation on the quality of life in cities and its function in urban environments, this study proposes a critical reflection on the role of vegetation in urban ecosystems, through a narrative review based on scientific articles, books, theses and dissertations on the subject. This narrative review addressed the urban ecosystems against the intense urban growth and its consequent deterioration of environmental quality provided the urban population. Thus, this narrative review has allowed a better understanding of the influence of vegetation on the quality of life in cities, establishing the vegetation exerts specific ecosystem functions, which in large part, are completely ignored by urban planning. Still, the analysis of local studies on the vegetation cover in Rondonópolis allowed understand how this city booming, organizes and maintains the vegetation in its urban space.
\end{abstract}

Keywords: Urban Ecosystems. Urban trees. Environmental Quality. 
Atualmente os ambientes urbanos são o local de vida de mais da metade da população da Terra e a tendência é que o processo de urbanização siga aumentando. De acordo com McDonnell e MacGregor-Fors (2016), pouco mais de 4 bilhões de pessoas, cerca de $54 \%$ da população global, vivem em cidades e este percentual deverá se elevar a $68 \%$ em 2050.

O processo de urbanização propicia um visível distanciamento entre sociedade e natureza, ao passo que as cidades tornam-se espaços com formas cada vez mais artificiais. De acordo com Cavalheiro (2009), além de uma paisagem artificial, as atividades provenientes da concentração humana nos espaços urbanos provocam uma ruptura no funcionamento do ambiente natural.

A ausência de elementos naturais, somada às consequências negativas da urbanização, como a poluição, a impermeabilização do solo e canalização de córregos, compromete a qualidade ambiental no meio urbano. Com a tendência de crescimento urbano, a preocupação recai sobre a qualidade ambiental proporcionada nestes espaços (ANGEOLETTO, 2012; MECDONNELL; MACGREGOR-FORS, 2016).

A cobertura vegetal possui funções ecossistêmicas importantes que garantem um ambiente propício ao bem-estar da população urbana, constituindo-se em elementos essenciais na paisagem urbana. Apesar de seus benefícios, faz-se necessário criar formas de favorecer a execução de cobertura vegetal, sobretudo nos locais de maior adensamento humano. (ANGEOLETTO, 2008; NUCGI, 2008; BARGOS; MATIAS, 2011, NETTO; SILVA, 2011; ALVES, 2012).

A falta de conhecimento sobre os serviços ecossistêmicos desempenhados pela cobertura vegetal urbana restringe a sua função meramente ao embelezamento da cidade, ignorando a grande maioria de seus benefícios ao meio urbano. Desta forma, o presente estudo tem por objetivo compreender as vantagens da cobertura vegetal para a qualidade de vida urbana, estabele- 
cendo como esta qualidade é mensurada por meio da utilização de índices, bem como refletir sobre o manuseio da cobertura vegetal nativa no processo de formação e expansão do espaço urbano.

Diante do crescimento urbano esperado para as próximas décadas, aumenta a importância de estudos que visem a aprimorar a qualidade de vida nestes ambientes. Assim, o presente estudo buscou, ainda, abordar aspectos relativos à cobertura vegetal urbana em Rondonópolis - MT, um município de médio porte que vivencia um processo de crescimento acelerado desde a década de 70 . 


\section{Materiais e Métodos}

\section{Identificação da Área de Estudo}

Rondonópolis localiza-se na região sudoeste do Estado de Mato Grosso, a 212 km da capital Cuiabá (Figura 1). Situada no bioma do Cerrado, possui uma área de $4.159,118 \mathrm{~km}^{2}$ e uma população estimada em $2015 \mathrm{de}$ 215.320 habitantes (IBGE). O clima é tropical com alternância de estação chuvosa (verão) e seca (inverno). As temperaturas elevadas acontecem praticamente em todas as estações do ano (SETTE, 1996).

Figura 1 - Localização de Rondonópolis - MT

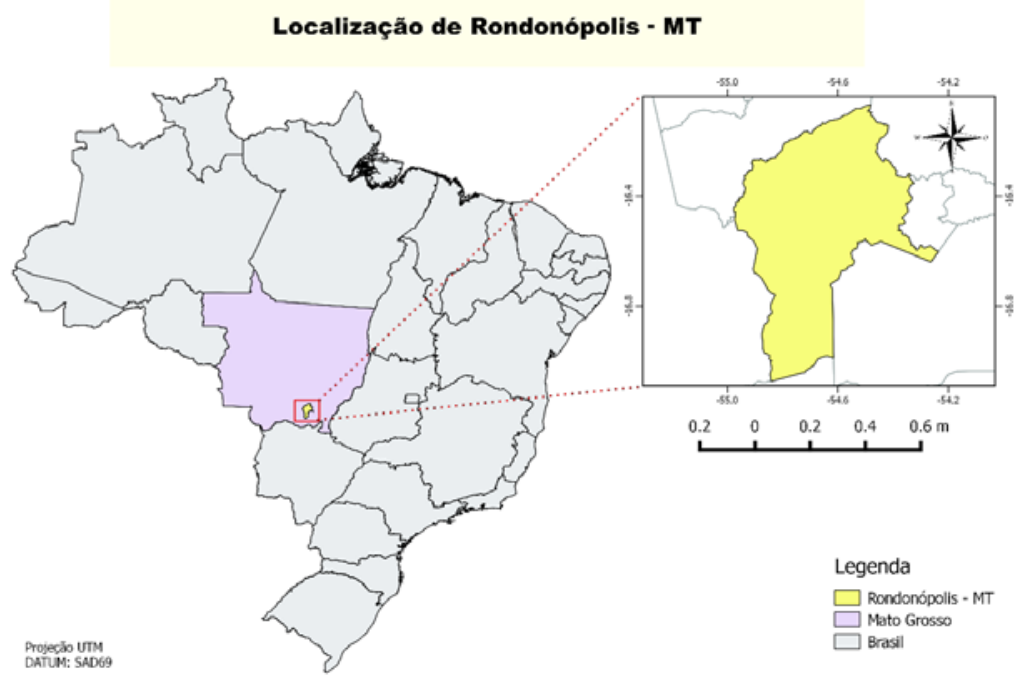

Fonte: Elaborada pelo autor.

Rondonópolis desempenha um papel significativo no cenário econômico regional devido a sua estratégica localização geográfica, no contexto das relações com o mercado de consumo. Além de sua localização privilegiada, no contexto do escoamento da produção de grão de todo o Estado de Mato Grosso, no eixo de duas importantes rodovias federais (BR 163 e 
BR 364), outros fatores, como a modernização da agricultura, o crescimento dos serviços relacionados ao mercado agrícola e consequente atração de trabalhadores em busca de oportunidades, fizeram com que Rondonópolis experimentasse altos índices de expansão urbana desde a década de 80 (NEGRI, 2008; DEMAMANN, 2011).

Como a maioria das cidades de porte médio, Rondonópolis caracteriza-se por apresentar um acelerado crescimento urbano em área e população (NEGRI, 2008). De acordo com o Instituto de Pesquisa Econômica Aplicada - Ipea (INSTITUTO..., 2011), as cidades médias crescem em média $1,51 \%$ ao ano, cabendo assim ressaltar que entre 1991 e 2000 Rondonópolis apresentou um crescimento acima da média, representando o dobro de crescimento esperado para uma cidade de médio porte.

\section{Procedimentos Metodológicos}

Buscando compreender a influência da cobertura vegetal na qualidade de vida nas cidades e sua função nos ambientes urbanos, o presente estudo propõe uma reflexão crítica sobre o papel da cobertura vegetal nos ecossistemas urbanos. Realizou-se então uma revisão narrativa com base em artigos científicos, livros, teses e dissertações sobre a temática.

De acordo com Rother (2007), uma revisão narrativa é apropriada para descrever e discutir o desenvolvimento ou o "estado da arte" de um determinado assunto, sob o ponto de vista teórico ou conceitual. Ela se constitui em uma análise da literatura científica na interpretação e análise crítica do autor, contribuindo para o debate de determinadas temáticas.

A presente revisão narrativa abordou os ecossistemas urbanos diante do intenso crescimento das cidades e sua consequente deterioração da qualidade ambiental proporcionada à população que convive nestes espaços. Buscou-se ainda levantar os benefícios da cobertura vegetal nos ambientes urbanos, estabelecendo o papel dos índices utilizados na mensuração da cobertura vegetal urbana. 
A supressão da cobertura vegetal e impermeabilização do solo são as principais características dos espaços urbanizados. Assim, buscou-se abordar aspectos relevantes sobre as áreas verdes no processo de formação e expansão do espaço urbano.

Rondonópolis é um município que vivencia um processo de crescimento acelerado vinculado principalmente à expansão da fronteira agrícola a partir da década de 70. Apesar da carência de estudos sobre a flora urbana em Rondonópolis, o presente estudo buscou abordar aspectos importantes em trabalhos locais, leis e portarias municipais, sobre os recursos vegetais no município.

\section{Resultados e Discussões}

\section{Ecossistemas Urbanos}

De acordo com a Secretariat of the Convention on Biological Diversity (2012), espera-se que as áreas urbanizadas tripliquem entre 2000 e 2030 . O Relatório sobre a população mundial da Organização das Nações Unidas ONU (2014) (Gráfico 1) aponta um crescimento da população urbana em 200 milhões neste mesmo período.

Gráfico 1 - População Urbana e Rural no Mundo, 1950-2050

População Urbana e Rural no Mundo, 1950 - 2050

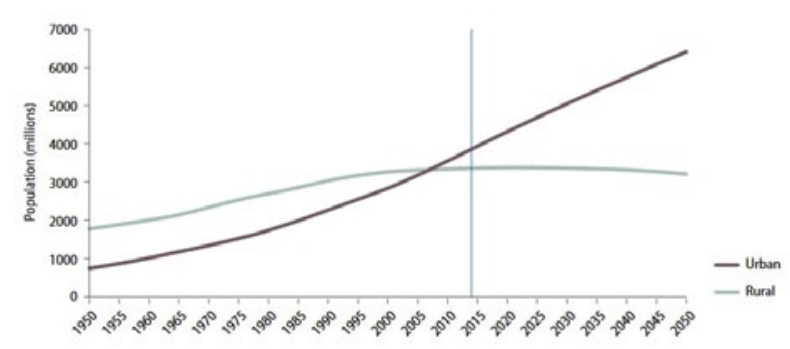

Fonte: Adaptado de ONU (2014). 
Com este crescimento, a tendência é que áreas destinadas à produção de alimentos e energia cresçam proporcionalmente à demanda populacional.

Angeoletto (2012) refere-se às cidades como ecossistemas pequenos, considerando-se a área ocupada, porém imensos em termos de impactos. Fiorini, Souza e Mercante (2013) mencionam que espacialmente as cidades ocupam um percentual entre $1 \%$ e $5 \%$ da parte terrestre do globo; já Liu (2014) destaca algo entre $0,6 \%$ e $3 \%$. Ainda que este percentual global seja pequeno, por serem dependentes de trocas com áreas externas, elas influenciam todo o globo por meio de seus imensos fluxos de entrada e saída (ANGEOLETTO, 2012; FIORINI; SOUZA; MERGANTE 2013).

A zona de influência que as cidades exercem sobre a biosfera não se refere apenas à produção de alimentos, mas sobretudo à geração de energia e bens de consumo (NETTO; SILVA, 2011; FIORINI; SOUZA; MERCANTE, 2013; ANGEOLETTO; SANTOS, 2015). Esta relação coloca o ser humano como principal organismo dos ecossistemas urbanos, pois, ao desenvolverem suas atividades nestes espaços, necessitam de uma quantidade de energia além daquela demandada para a manutenção dos seus processos vitais (NETTO; SILVA, 2011).

A energia extra produzida pelo homem é utilizada, entre outras coisas, para potencializar sua capacidade de locomoção, controlar a luminosidade e a temperatura de ambientes construídos e produzir ferramentas e produtos essenciais para a manutenção da sociedade (FIORINI; SOUZA; MERCANTE, 2013). Essa crescente geração de energia para satisfazer as necessidades humanas e seus padrões de consumo, no entanto, gera resíduos e degradação ambiental além da capacidade natural de regeneração, desencadeando uma relação insustentável e em desequilíbrio.

Odum (1996) ao refletir sobre a preocupação humana de explorar o máximo potencial de produção, observa que o homem não vive só de alimentos, mas também necessita de uma atmosfera equilibrada quanto a $\mathrm{CO}_{2}$ e $\mathrm{O}_{2}$. De fato, um ambiente que proporcione boas condições de vida, 
como água potável, moradia segura contra enchentes e inundações, conforto térmico, ar despoluído e outros serviços ecossistêmicos são essenciais para qualidade de vida nas cidades.

Arbitrariamente, o homem compromete a qualidade do ambiente em que vive em nome da satisfação das necessidades de consumo como requisito para melhoria da qualidade de vida, porém esta é comprometida se as condições físicas, químicas e biológicas do ambiente em que se vive forem degradadas.

Os problemas ambientais que deterioram a qualidade de vida nas cidades são reflexo da deterioração das relações entre a sociedade e o meio ambiente, ou seja, as relações promovidas entre o capital e o trabalho engendradas pelas leis de mercado que criam necessidades e acentuam desequilíbrios no ambiente urbano (BOERSEMA, 2009; BARBOSA; NASCIMENTO JÚNIOR, 2009).

Apesar da influência que as áreas urbanas exercem sobre a biosfera, poucos são os estudos a respeito da ecologia dos sistemas ecológicos urbanos, mostrando a pouca importância dada à natureza nas cidades (GRIMM; REDMAN, 2004; GRIMM et al., 2008; ANGEOLETTO; SANTOS, 2015). Assim sendo, pensar o desenvolvimento urbano com menor impacto à biosfera, mais amigável à biodiversidade e que proporcione melhor qualidade de vida, é um dos grandes desafios a serem enfrentados no século 21 (ANGEOLETTO; SANTOS, 2015).

De acordo com Willians (2013), a maior parte do crescimento urbano atual acontece em hotspots de biodiversidade, como o Cerrado e a Mata Atlântica. Assim, aumenta a importância de compreendermos os fatores ambientais e sociais que influenciam a cobertura vegetal nos ecossistemas urbanos, de maneira tanto a incrementá-la, quanto a aprimorá-la para o suporte à biodiversidade. 
Preservar a biodiversidade neste novo planeta urbano exige ir além das tradicionais abordagens e conservação do que se define como "ecossistemas naturais", considerando as cidades como uma nova classe de ecossistemas moldados pelas interações dinâmicas entre sistemas ecológicos e naturais (SECRETARIAT..., 2012). A biodiversidade é fundamental para a manutenção da vida humana no planeta, sendo necessário que as cidades sejam planejadas para propiciar a manutenção e incremento da variedade de espécies (NETTO; SILVA, 2011).

Figura 2 - Linhas sugeridas para incrementar a biodiversidade urbana

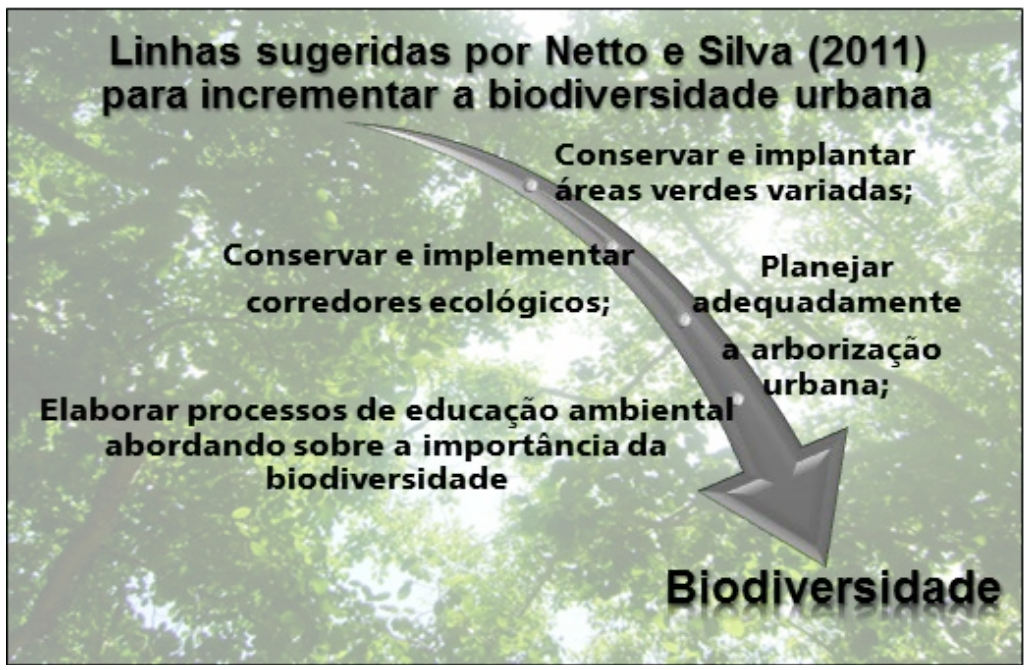

Fonte: NETTO; SILVA (2011). Organizado pelo autor.

As linhas sugeridas para incremento da biodiversidade urbana por Netto e Silva (2011) (Figura 2) deixam evidente a relação entre cobertura vegetal e biodiversidade. Isso posto, é importante que a arborização urbana seja planejada em quantidade, forma e diversidade que proporcionem o máximo de sua função nos ecossistemas urbanos: aumentar a biodiversidade e propiciar qualidade ambiental. 
A biodiversidade urbana é a variedade e riqueza de organismos vivos e a diversidade de habitats encontrados dentro e às margens dos assentamentos humanos. Nas cidades, a biodiversidade expõe as pessoas à natureza, proporcionando oportunidades para recreação, saúde, relaxamento e coesão comunitária (SECRETARIAT..., 2012).

\section{Beneficios da Cobertura Vegetal e sua Importância nos Ambientes Urbanos}

A cobertura vegetal urbana contribui para a manutenção da qualidade ambiental e melhoria da qualidade de vida nas cidades (INTER AMERICAN..., 1997). Desta forma, diversos autores estabelecem que a manutenção das áreas verdes urbanas é justificada pelo seu potencial em propiciar qualidade ambiental à população (ANGEOLETTO, 2008; NUCGI, 2008; BARGOS; MATIAS, 2011; NETTO; SILVA, 2011; ALVES, 2012).

Ela interfere diretamente na qualidade de vida dos seres por meio das funções sociais, ecológicas, estéticas e educativas que exercem nos ecossistemas. Alves (2012) defende que a presença de cobertura vegetal urbana está relacionada a uma série de funcionalidades ambientais e que sua presença é essencial na paisagem urbana, podendo amenizar ou resolver diversos problemas ambientais.

Serviços ecossistêmicos ou ambientais são as contribuições diretas e indiretas dos ecossistemas para o bem-estar humano. Entre os serviços ecossistêmicos proporcionados pela cobertura vegetal nas cidades pode-se citar a regulação do clima, absorção da radiação solar, filtro de poeiras, armazenamento de $\mathrm{CO}_{2}$, barreira para ventos, melhoria da qualidade do ar, promoção de resfriamento por evaporação, sombreamento e geração e convecção de ar, interceptação de chuvas, envolvendo também aspectos psicológicos, como o aumento da satisfação e redução do estresse, e aspectos econômicos, como a valoração monetária dos serviços ecossistêmicos (SECRETARIAT..., 2012). 
A Secretariat of the Convention on Biological Diversity (2012) estabelece que espaços urbanos com 50\%-90\% de superfície impermeável podem perder 40\%-83\% da água da chuva para o escoamento superficial, ao passo que áreas vegetadas perdem apenas por volta de $13 \%$ da água da chuva em eventos semelhantes de precipitação.

Devido as suas características multifuncionais, a cobertura vegetal urbana oferece importantes benefícios, como a redução na erosão, aumento da fertilidade do solo, ampliação dos valores estéticos, redução dos gastos com aquecimento, ventilação e ar condicionado. (ANGEOLETTO, 2000, 2012; SECRETARIAT..., 2012). Nucci e Cavalheiro (1999), entre as funcionalidades ambientais da vegetação em áreas urbanas, mencionam ainda a proteção das nascentes e mananciais, organização e composição de espaços no desenvolvimento das atividades humanas, valorização visual e ornamental, recreação, quebra de monotonia das cidades, cores relaxantes, estabelecimento de uma escala intermediária entre a natural e a construída.

Entre os benefícios psicológicos, a presença de cobertura vegetal urbana pode mitigar precursores psicológicos da violência como a irritabilidade, bastante presente no dia a dia urbano, reduzir a ansiedade, incrementar o relaxamento, reduzir o estresse, rejuvenescer a cidade, proporcionando aos moradores uma sensação de paz e tranquilidade (TIAN et al., 2011; SECRETARIAT..., 2012).

É possível, portanto, que as cidades sejam espaços que proporcionem maior qualidade ambiental se seu planejamento urbano e os próprios moradores priorizarem e propiciarem a inserção de cobertura vegetal, pensando nos imensos benefícios que ela traz à vida urbana, a ponto de ser considerada um dos principais indicadores de qualidade ambiental urbana. 


\section{Cobertura Vegetal, Qualidade e Planejamento Ambiental}

O processo de urbanização revela sinais claros de um "desenvolvimento" que não primou por relações equilibradas entre a cidade e a natureza (NUCCI, 2008; ALVES, 2012). O planejamento ambiental urbano surge como forma de gerir os conflitos existentes entre sociedade e natureza (ALVES, 2012).

A análise ecossistêmica dos ambientes urbanos possibilita enxergar a relação entre diversos processos ecológicos, identificando pontos de ação para melhoria da qualidade ambiental (NETTO; SILVA, 2011). A cobertura vegetal urbana, dessa forma, precisa ser encarada como um elemento fundamental desse ecossistema.

Os serviços ecossistêmicos da cobertura vegetal podem ser utilizados no planejamento urbano a fim de melhorar a qualidade ambiental. Rahman, Armson e Ennos (2014) estabelecem que é possivel comparar a tolerância de diferentes espécies de árvores quanto ao desempenho e estresse, selecionando tipos de plantas adequadas para maximizar serviços específicos do ecossistema.

Muito embora se reconheça sua funcionalidade nos ecossistemas urbanos, a instituição de manutenção adequada da cobertura vegetal nas cidades ainda é um desafio (ALVES, 2012). Esta dificuldade pode ser atribuída a diversos fatores de ordem social, econômica e até mesmo pela falta de conhecimento sobre os benefícios e importância das árvores nos ecossistemas urbanos.

Angeoletto (2012), ao investigar a disposição dos moradores de quatro bairros da cidade de Sarandi - PR - no plantio de árvores em quintais privados, percebeu que, em não raros casos, a cobertura vegetal compete com o desejo de ampliação da residência ou inserção de anexos como garagem e churrasqueira. Assim, a falta de cobertura vegetal nos quintais era justificada pelos moradores pela falta de espaço disponível para tal. 
Eckbo (1977) já criticava a falta de entusiasmo com as árvores no meio urbano ao afirmar que nas cidades, especialmente no centro, a vegetação constituía-se apenas em um elemento decorativo. Ironicamente ele afirma que se as plantas fossem de plástico não faria diferença alguma, uma vez que não são vistas com nenhuma função específica. Para ele, as árvores representam um indicador da saúde urbana, pois por serem mais sensíveis e vulneráveis que as pessoas, quando não estiverem se dando bem numa cidade, com certeza as pessoas não estarão melhores.

Nota-se que a arborização urbana é realizada para cumprir formalidades, não lhe sendo atribuída nenhuma função ecossistêmica. Assim, a população urbana só plantará árvores à medida que visualizar benefícios que superem o incômodo ocasionado pela queda de folhas e gastos com podas.

Os processos de educação ambiental, portanto, são essenciais para disseminação da importância da cobertura vegetal e sua instituição adequada para o máximo desempenho de suas funções ecossistêmicas. Bressane et al. (2015) recomendam que programas de educação ambiental devem ser considerados fundamentais, pois a conservação das áreas verdes é influenciada pela forma de uso e comportamento da população usuária.

\section{As Áreas Verdes na Formação do Espaço Urbano}

Para dar forma às cidades geralmente a vegetação natural é suprimida nos processos de terraplanagem. Neste processo, além da vegetação suprimida para dar espaço a casas e empreendimentos, há uma enorme perda de qualidade ambiental, com prejuízos à biodiversidade da fauna e flora e à qualidade de vida humana.

A supressão da cobertura vegetal somada à impermeabilização demasiada do solo se constituem nas principais características dos espaços urbanizados. Cavalheiro (2009) afirma que a urbanização cobre ou impermeabiliza grande quantidade de áreas, com isso solos férteis, biótipos, ecossistemas raros e valiosos são perdidos. 
Angeoletto e Santos (2015) afirmam que apesar dos problemas decorrentes da urbanização, as cidades possuem um enorme potencial para a realização de cobertura vegetal desde que haja um planejamento neste sentido. Berland (2012) analisou diversas classes de uso do solo na região metropolitana de Minnesota, EUA, entre os anos de 1937 e 2009 para estabelecer como a cobertura vegetal se comportou no processo de produção do espaço urbano, constatando que áreas urbanizadas ficam atrás somente das florestas em quantidade de árvores.

Muito embora as cidades possuam este potencial de cobertura vegetal e consequentemente de incrementar a biodiversidade, há uma disparidade no acesso a áreas verdes entre diferentes níveis de renda. Além do mais, existem alguns elementos dificultadores da introdução de árvores nas cidades e especialmente nos bairros de menor renda.

O adensamento urbano nos bairros de baixa renda é uma tendência no Brasil. Esse tipo de parcelamento do solo dificulta a inserção de cobertura vegetal arbórea, predestinando essa população a uma menor quantidade de cobertura vegetal e consequentemente menor qualidade ambiental.

Haughton (1997), ao defender esse tipo de parcelamento do solo urbano, afirma que cidades mais compactas podem conter menos natureza, uma vez que a prioridade é adensar a urbanização evitando a tomada de solo agrícola para o desenvolvimento urbano. $\mathrm{O}$ autor defende também que expor a população a uma menor qualidade ambiental, menos contato com a natureza, é um "mal necessário" a fim da preservação do solo agrícola e da produção de alimento para a população urbana.

Angeoletto (2008) destaca que os méritos das cidades compactas são evidentes, mas a urbanização nestes padrões deve ser discutida de maneira desapaixonada, levando em consideração seus prós e contras. Da mesma forma Lago (2011) avalia que analisar o bem-estar da população urbana em relação às características do domicílio é dificultada pela escassez de variáveis que efetivamente indiquem um padrão de conforto nos locais de moradia. 
O aumento populacional e a produção de alimentos são, de fato, uma preocupação iminente, pois aumentar a produção representa expansão de maiores áreas destinadas para atender essa necessidade. Existe, portanto, um conflito de interesses no uso do solo, não sendo desejado que cidades se expandam demasiadamente sobre solos agrícolas.

Terradas (2001) conclui que independentemente de sua maior ou menor compactação, as cidades precisam ser intensas, ou seja, é necessário que elas planejem bem seus espaços, evitando os vazios urbanos, propiciem uma urbanização mais amigável à realização de cobertura vegetal e tenham padrões de consumo mais sustentáveis.

\section{Análise dos Índices de Cobertura Vegetal}

Os índices de cobertura vegetal (ICV) são utilizados como indicadores de qualidade ambiental nas cidades. Sua finalidade é mensurar os serviços ecossistêmicos proporcionados pela cobertura vegetal estabelecendo se estes estão de acordo com o mínimo recomendado.

No Brasil, grande parte dos estudos segue a recomendação da Sociedade Brasileira de Arborização Urbana, que estabelece um índice mínimo de $15 \mathrm{~m}^{2}$ de área verde por habitante. (SOCIEDADE..., 1996).

Costa e Ferreira (2009), em uma visão bastante simplista, entendem que o cálculo de índices de área verde serve como indicador de presença ou ausência delas, buscando analisar se a área de estudo está dentro do recomendado ou não. Freire et al. (2012) de forma mais abrangente, entendem que os índices de área verde visam a compreender a realidade dos espaços públicos, servindo como instrumentos para a realização de um planejamento urbano e ambiental mais condizente com as necessidades da comunidade local.

Esta visão simplista, entretanto, tem predominado nos estudos que aplicam índices de cobertura vegetal no Brasil. Via de regra, nota-se o emprego de análises quantitativas que apenas informam o percentual de área 
verde e estabelecem se estão dentro do recomendado ou não, dando pouca ênfase nos serviços ambientais proporcionados pelas áreas verdes, na qualidade dessa vegetação ou mesmo nas espécies utilizadas, como se, grosso modo, todas as árvores fossem iguais. $\mathrm{Na}$ realidade, o que se pretende destacar é que $15 \mathrm{~m}^{2}$ de Oitis (Licania Tomentosa) não proporcionam os mesmos serviços ambientais que $15 \mathrm{~m}^{2}$ de Dedo-do-diabo (Euphorbia tirucalli), no entanto estes cálculos não consideram as especificidades de cada espécie, bem como o contexto no qual estão inseridas.

Costa e Ferreira (2009) destacam que ao identificar a presença de áreas verdes a preocupação deve centrar-se nas condições em que essas áreas se encontram, se são utilizadas para o fim a que foram destinadas, se sua localização é adequada e/ou se atendem às necessidades daquela comunidade.

O índice mínimo recomendado pela Sociedade Brasileira de Arborização Urbana teve como objetivo estabelecer um percentual mínimo de áreas verdes para as cidades de Londrina e Ibiporã, no entanto pela falta de outros parâmetros, este índice é empregado em todos os Estados brasileiros. Cabe refletir ainda que o Brasil possui seis biomas, destacando que cada um destes tem características próprias, como clima, relevo, espécies endêmicas. Assim, utilizar os mesmos parâmetros para mensurar qualidade ambiental em locais com características tão diferentes seria no mínimo questionável quanto a sua eficácia.

Levando em consideração serviços ecossistêmicos proporcionados pela cobertura vegetal, entre eles o equilíbrio da temperatura, Luz e Rodrigues (2012) utilizam um parâmetro que estabelece que cidades, distritos e bairros devem apresentar um índice mínimo de 30\% de cobertura vegetal para garantir os serviços ambientais que proporcionam o equilíbrio da temperatura em meio urbano. Os autores analisam ainda que com ICV inferiores a $5 \%$ tem-se a formação de desertos florísticos, nos quais existem elevada temperatura, ausência de áreas verdes e desconforto térmico. 
Como constata Iwama (2014), entretanto, a grande quantidade de árvores em calçadas, por si só, não garante qualidade ambiental, sendo necessário atentar para fatores como diversidade, densidade da copa e a qualidade das árvores inseridas.

Entre os parâmetros utilizados para quantificação de cobertura vegetal em meio urbano pode-se citar o Índice de Árvores/Km Linear. Este método tem por finalidade quantificar o número de árvores por quilômetro linear de calçada. Segundo Iwama (2014), cem árvores por quilômetro seria um índice considerado ideal, o que representa uma árvore a cada 10 metros. $\mathrm{O}$ autor conceitua ainda que quantidades abaixo de 60 árvores por $\mathrm{km}$ necessitam de atenção com relação à baixa qualidade ambiental proporcionada pela pouca quantidade de plantas (Tabela 1).

Tabela 1 - Modelo de referência para quantificação de árvores/km linear proposto por Iwama (2014)

\begin{tabular}{|l|l|}
\hline 100 árvores $/ \mathrm{km}$ & Baixa atenção; \\
\hline 60 a 100 árvores $/ \mathrm{km}$ & Média atenção; \\
\hline 40 a 60 árvores $/ \mathrm{km}$ & Alta atenção; \\
\hline 10 a 40 árvores $/ \mathrm{km}$ & Muito alta atenção; \\
\hline$<10$ árvores $/ \mathrm{km}$ & Extremamente alta atenção \\
\hline
\end{tabular}

Fonte: IWAMA (2014). Organizada pelo autor.

A expressiva maioria dos trabalhos de quantificação de cobertura vegetal no meio urbano, entretanto, utiliza o Índice de Cobertura Vegetal (ICV), que é a quantidade de cobertura vegetal $\left(\mathrm{m}^{2}\right)$ presente na cidade ou no bairro dividida pelo número de moradores, obtendo-se dessa forma uma quantidade de cobertura vegetal per capita. Da mesma forma, este cálculo também é utilizado para se obter o Índice de Áreas Verdes (IAV), tendo como finalidade determinar a quantidade de cobertura vegetal disponível a cada morador como indicador de qualidade ambiental (TOLEDO; MAZZEI; SANTOS, 2009; FREIRE et al., 2012; COSTA; FERREIRA, 2009; LUCON; PRADO FILHO; SOBREIRA, 2013). 
Estes índices relacionam a qualidade ambiental proporcionada pela cobertura vegetal na proporção entre esta e a densidade populacional. Um dos problemas, ao se realizar comparativos destes índices é que muitas vezes altos índices de cobertura vegetal em uma região não indicam necessariamente elevada qualidade ambiental, uma vez que este índice pode ter sido obtido em razão da baixa densidade populacional do bairro e não necessariamente por ser bem arborizado.

Rosset (2005) estabelece que comparar índices de cobertura vegetal pode ser algo bastante complexo pela falta de padrões metodológicos. Desta forma, necessita-se de uma análise mais integrada da cobertura vegetal urbana.

Uma análise mais integradora da cobertura vegetal urbana deve atentar para o raio de influência, que é a área que os serviços ecossistêmicos desta cobertura vegetal podem alcançar. Ao se comparar bairros, por exemplo, é preciso ter em mente que mesmo que o bairro não possua área verde, ele pode estar no raio de influência de uma área verde da vizinhança, pois os serviços ambientais não reconhecem os limites físicos do bairro, mas abrangem uma área de alcance, conforme estabelece Zanin (2002).

Além dos índices que visam a determinar simplesmente a quantidade de cobertura vegetal, existem índices que têm por objetivo caracterizar esta cobertura vegetal, oferecendo aspectos relevantes para a realização de análise integrada da arborização urbana, como qualidade, disposição, diversidade de espécies, densidade da copa, entre outros aspectos. Destaca-se a seguir alguns índices bastante utilizados para análise de cobertura vegetal (Tabela 2):

Tabela 2 - Índices qualitativos e características

\begin{tabular}{|c|c|}
\hline ÍNDICES & CARACTERÍSTICAS \\
\hline 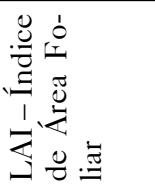 & $\begin{array}{l}\text { É utilizado na escolha de espécies arbóreas utilizadas na arboriza- } \\
\text { ção urbana. O cálculo da área foliar é a densidade da copa em m², } \\
\text { assim espécies com maior LAI e consequente maior absorção de } \\
\text { radiação solar são recomendadas para arborização de ruas e calçadas } \\
\text { (MENDES et al., 2014). }\end{array}$ \\
\hline
\end{tabular}




\begin{tabular}{|c|c|}
\hline 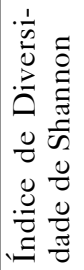 & $\begin{array}{l}\text { Mensura a diversidade de espécies encontradas em determinado } \\
\text { local, levantando o número de indivíduos de cada espécie, o nú- } \\
\text { mero de espécies (riqueza de espécies) calculando a proporção } \\
\text { dos indivíduos de cada espécie pelo número total de indivíduos na } \\
\text { comunidade (WEAVER; SHANNON, 1949). }\end{array}$ \\
\hline 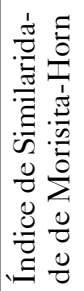 & $\begin{array}{l}\text { O índice de similaridade de Morisita-Horn, entre os índices nor- } \\
\text { malmente usados para comparações de espécies de amostras de } \\
\text { sítios distintos é considerado como o mais robusto e preciso. Ele } \\
\text { se baseia na abundância de espécies e não apenas na presença ou } \\
\text { ausência delas, variando de } 0 \text { quando não há nenhuma similaridade } \\
\text { na comparação de espécies entre os sítios à } 1 \text { apresentando absoluta } \\
\text { sobreposição ou overlap entre as espécies dos sítios (MCINTYRE } \\
\text { et al., 2001). }\end{array}$ \\
\hline
\end{tabular}

Fonte: MENDES et al., 2014; WEAVER; SHANNON, 1949;

MCINTYRE et al., 2001. Organizada pelo autor.

\section{Áreas Verdes em Rondonópolis - MT}

Rondonópolis vivencia um processo de crescimento acelerado vinculado aos vários períodos econômicos pelo qual passou o município, por meio principalmente da expansão da fronteira agrícola a partir da década de 70, baseado na pecuária extensiva e na monocultura da soja (NEGRI, 2008; PEREIRA, 2009; ROHLING; SILVA, 2012). Em relação aos recursos vegetais em Rondonópolis, nota-se a carência de literatura acadêmica que aborde aspectos relacionados à flora urbana.

De modo geral, escassos estudos têm se dedicado à classificação da flora regional na Região Sudeste de Mato Grosso. Devido ao processo atual de expansão da urbanização e uso intensivo do solo nessa região, espécies vegetais podem simplesmente desaparecer sem a prévia classificação (OLIVEIRA; NASGIMENTO, 2004). 
Oliveira e Nascimento (2004), em tom de preocupação, observam que por influência do agronegócio, houve uma drástica perda da flora característica do Cerrado na Região Sudeste do Estado. O pouco do Cerrado que ainda se nota nesta região se resume a pequenas áreas preservadas por exigência da lei.

Rohling e Silva (2012), em um estudo sobre fragmentos de Cerrado em uma área de transição entre a zona rural e a periferia do perímetro urbano de Rondonópolis, observam que os remanescentes nativos de Cerrado apresentam-se intensamente fragmentados. Estes pequenos fragmentos, quase sempre desconectados, não são capazes de atuar favorecendo a manutenção da biodiversidade.

Um estudo realizado por Pereira (2009) buscou verificar a perda de cobertura vegetal no perímetro urbano do município de Rondonópolis, entre os anos de 1986 e 2008, relacionando ao processo de ocupação urbana ocorrido nesse período. Esta análise temporal e espacial da cobertura vegetal com base em imagens de satélite constatou uma perda de $48 \%$ de cobertura vegetal no período compreendido pelo estudo.

Em meio a este cenário, o Horto Florestal de Rondonópolis destaca-se como uma importante amostra dos recursos vegetais da região. De acordo com a classificação de espaços livres sugerida por Bargos e Matias (2011), o Horto Florestal de Rondonópolis enquadra-se na categoria de Parque Urbano por se tratar de uma área verde de grande extensão com funções ecológicas, estéticas e de lazer.

O Plano Diretor do município de Rondonópolis estabelece como objetivos do Horto Florestal a reprodução de espécies da flora, projetos de experimentação científica e paisagismo, bem como a educação ambiental e a pesquisa científica. O raio de influência dos serviços ecossistêmicos proporcionados pelos parques urbanos atinge até $3.000 \mathrm{~m}$, segundo classificação de Zanin (2002) (Tabela 3). Assim sendo, o raio de influência do Horto Florestal atinge boa parte da área central da cidade. 
Tabela 3 - Classificação de Zanin (2002)

para Raios de Influência de Áreas Verdes

\begin{tabular}{|l|l|}
\hline Categoria de área verde & Distância do Raio de Influência \\
\hline Canteiros Centrais & $500 \mathrm{~m}$ \\
\hline Praças & $800 \mathrm{~m}$ \\
\hline Parques & $3.000 \mathrm{~m}$ \\
\hline
\end{tabular}

Fonte: ZANIN (2002). Organizada pelo autor.

Um estudo de identificação de espécies arbóreas nativas do Cerrado no Horto Florestal de Rondonópolis realizado por Oliveira e Nascimento (2004) catalogou 91 espécies preservadas com a criação do parque. As espécies catalogadas poderiam servir como suporte para o poder público na escolha de espécies para arborização viária do município, haja vista que são endêmicas da região.

A arborização viária do município é regulamentada pelo Plano Diretor e estabelece que o projeto de arborização e paisagismo devem obedecer às normas do Código Ambiental do município, sendo analisados pelo órgão municipal competente, bem como a escolha das espécies empregadas devem ser autorizadas pela Secretaria Municipal de Meio Ambiente (BRASIL, 2006).

O Plano Diretor do Rondonópolis estabelece ainda a obrigatoriedade de destinar $10 \%$ do plano urbanístico para áreas verdes, exceto em loteamentos com área abaixo de três hectares (BRASIL, 2006), no entanto não existem estudos que analisam se os loteamentos criados após a aprovação do Plano Diretor têm cumprido esta obrigatoriedade.

A valorização do preço da terra urbana em Rondonópolis tem propiciado a instalação de loteamentos em padrões cada vez mais adensados. As dimensões dos lotes, bem como a metragem dos passeios públicos, afetam diretamente a quantidade de cobertura vegetal existente nas cidades. 
O Plano Diretor do município regulamenta a largura mínima dos lotes em $5 \mathrm{~m}$ (cinco metros) de frente e área total mínima de $125 \mathrm{~m}^{2}$ em assentamentos de interesse social (BRASIL, 2006). Estas medidas não favorecem a fixação de cobertura vegetal, principalmente de porte arbóreo, nos quintais das residências, privando a população dos benefícios ecossistêmicos proporcionados pela vegetação para a manutenção da qualidade ambiental.

Se a cidade continuar expandindo-se nesses padrões de parcelamento do solo, resultará em um maior adensamento humano com menor quantidade de cobertura vegetal, ou seja, haverá uma redução no índice de cobertura vegetal por habitante. Um baixo índice de cobertura vegetal por habitante representa pouca qualidade ambiental, que afetará principalmente a população mais pobre, aumentando ainda mais a desigualdade social.

Outra tendência evidenciada na grande maioria dos municípios é a falta de diversidade de espécies utilizadas na arborização urbana e a pouca ênfase na introdução de espécies nativas. (ANGEOLETTO, 2012). Em Rondonópolis, a Secretaria Municipal de Meio Ambiente recomenda apenas 11 espécies para o plantio em áreas urbanas, das quais nenhuma é nativa do Cerrado.

$\mathrm{O}$ ato de restringir o número de espécies recomendadas para o plantio nos espaços urbanos é um fator que age diminuindo a diversidade de espécies empregadas. Em Rondonópolis não existem ações do órgão ambiental no sentido de aprimorar a diversidade das espécies arbóreas utilizadas, fazendo com que a paisagem da cobertura vegetal urbana seja massivamente representada pelos oitis.

Um estudo realizado por Duarte et al. $(2015)^{8}$ em um bairro do município de Rondonópolis constatou que do total de espécies utilizadas na arborização de calçadas $75,4 \%$ eram oitis. Este percentual é bastante elevado

8 In press. 
comparando-se a outros trabalhos produzidos na mesma região, os quais obtiveram 33,1\% em Várzea Grande-MT (MOURA; SANTOS, 2009) e 18,2\% em três praças pública de Cáceres-MT (ASSUNÇÃO, 2009).

A diversidade de espécies calculadas por meio do Índice de Shannon leva em consideração três variáveis: o número de espécies; a quantidade total de indivíduos de cada espécie; a abundância relativa de cada espécie, calculada pela proporção dos indivíduos de uma espécie pelo número total dos indivíduos na comunidade (ANGEOLETTO, 2012). Logo, poucas espécies recomendadas e a alta incidência de uma mesma espécie representaria um Índice de Shannon relativamente baixo, revelando pouca diversidade.

Santamour Júnior (2002) estabelece que a maior diversidade de espécies de árvores no ambiente urbano se faz necessária justamente para garantir o máximo de proteção contra pragas e doenças, e recomenda não exceder mais que $10 \%$ da mesma espécie, $20 \%$ de algum gênero e $20 \%$ de uma família botânica.

\section{Considerações Finais}

A presente revisão narrativa permitiu uma melhor compreensão da influência da cobertura vegetal na qualidade de vida nas cidades, estabelecendo que a cobertura vegetal exerce funções ecossistêmicas específicas, que na parte das vezes são completamente ignoradas pelo planejamento urbano.

Para melhor compreensão desta relação foi de fundamental importância trazer à luz algumas questões como ecossistemas urbanos, serviços ecossistêmicos desempenhados pela cobertura vegetal, quais os índices utilizados na mensuração da cobertura vegetal urbana e as áreas verdes em relação ao processo de expansão urbana. O aprofundamento teórico sobre estas questões permitiu compreender a função e benefícios da cobertura vegetal nos ecossistemas urbanos e sua relação com a qualidade ambiental. 
Apesar da escassez de estudos sobre a cobertura vegetal em esfera local, ou regional, a presente revisão narrativa revelou-se eficaz para alcançar os resultados almejados com a pesquisa.

A análise de estudos locais referentes à cobertura vegetal em Rondonópolis permitiu compreender como este município, em franca expansão, organiza e mantém a cobertura vegetal. O presente estudo evidenciou que Rondonópolis, além da perda de um percentual significativo da cobertura vegetal nativa (48\%) em seu processo de expansão urbana desde a década de 80 , executa uma cobertura vegetal com pouca diversidade e não existem ações para a introdução da diversidade de espécies no município.

Diante do crescimento urbano esperado para as próximas décadas, aumenta a importância de estudos que visem a aprimorar a qualidade de vida nestes ambientes. Nesse sentido, a cobertura vegetal torna-se um importante elemento na paisagem urbana devido as suas importantes funções ecossistêmicas que melhoram a qualidade ambiental.

É necessário, contudo, que as pessoas entendam a real importância e benefícios da cobertura vegetal no meio urbano, para que de fato ela seja mais valorizada pela população. Da mesma forma, o planejamento urbano deve priorizar seus benefícios ao estabelecer uma cobertura vegetal em forma, diversidade e quantidade que favoreçam suas funções ecossistêmicas, garantindo maior qualidade ambiental urbana.

\section{Referências}

ALVES, D. B. Cobertura vegetal e qualidade ambiental na área urbana de Santa Maria RS. 2012. Dissertação (Mestrado em Geografia) - UFSM, Santa Maria, 2012.

ANGEOLETTO, F. H. S. Pirajá, um bairro e um parque: a vegetação como fator de aumento da biodiversidade e da qualidade de vida nos biomas urbanos. 2000. Dissertação (Mestrado em Arquitetura e Urbanismo) - Universidade Federal da Bahia, Salvador, 2000. (Mimeo). 
ANGEOLETTO, F. H. S. Pelos quintais de Sarandi: ecologia urbana e planejamento ambiental. Maringá: Eduem, 2008.

. Planeta cidade: ecologia urbana e planejamento de cidades médias do Brasil. 2012. Tese (Doutorado em Ecologia e Meio Ambiente) - Universidade Autônoma de Madrid, Madrid, 2012.

ANGEOLETTO, F. H. S.; SANTOS, J. W. M. C. Los biólogos brasileños no habitan en el planeta ciudad por qué es urgente formar ecólogos urbanos. Revista Espaço Acadêmico, n. 165, p. 74-82, 2015.

ASSUNÇÃO, K. C. Levantamento quantitativo da arboriæação de praças da cidade de Cáceres-MT. 2009. Monografia (Engenharia Agronômica) - Unemat, Cáceres, 2009.

BARBOSA, V. L.; NASCIMENTO JÚNIOR, A. F. Paisagem, ecologia urbana e planejamento ambiental. Geografia, Londrina, v. 18, n. 2, p. 21-36, 2009.

BARGOS, D. C.; MATIAS, L. F. Áreas verdes urbanas: um estudo de revisão e proposta conceitual. Revista da Sociedade Brasileira de Arboriæação Urbana, Piracicaba, SP, v. 6, n. 3, p. 172-188, 2011.

BERLAND, A. Long-term urbanization effects on tree canopy cover along an urban-rural gradiente. Urban Ecosyst, n. 15, p. 721-738, 2012.

BOERSEMA, J. J. Environmental sciences, sustainability and quality. Principles of Environmental Sciences. Amsterdam: Springer, 2009. p. 3-4.

BRASIL. Lei Complementar n ${ }^{\circ} 43$, de 28 de dezembro de 2006. Plano Participativo Diretor de Rondonópolis. 2006.

CAVALHEIRO, F. Urbanização e alterações ambientais. In: SANTOS, D. G.; NUCCI, J. C. Paisagens geográficas: um tributo a Felisberto Cavalheiro. Campo Mourão: Ed. da Fecilcam, 2009. 196p.

COSTA, R. G. S.; FERREIRA, C. C. M. Análise do índice de áreas verdes (IAV) na área central da cidade de Juiz de Fora, MG. Revista da Sociedade Brasileira de Arborização Urbana, Piracicaba, SP, v. 4, n. 1, p. 39-57, 2009.

DEMAMANN, M. T. M. Rondonópolis - MT: campo, cidade e centralidades. 2011. Tese (Doutorado em Geografia) - USP, São Paulo, 2011.

ECKBO, G. O paisagismo nas grandes metrópoles. Revista Geografia e Planejamento. São Paulo: Ed. Cairu, 1977. 
FIORINI, A. J. C. E.; SOUZA, C. C.; MERCANTE, M. A. A pegada ecológica como instrumento de avaliação ambiental da cidade de Campo Grande, Mato Grosso do Sul. Sustentabilidade em Debate, Brasília, v. 4, n. 1, p. 231-248, jan./jun. 2013.

FREIRE, R. H. A. et al. Índice de áreas verdes para macrozona de consolidação de Paranavaí - PR. Revista da Sociedade Brasileira de Arborização Urbana, Piracicaba, SP, v. 7, n. 1, p. 1-22, 2012.

GRIMM, N. B.; REDMAN, C. L. Aprroaches to the Estudy of Urban Ecosystems: The Case of Central Arizona - Phoenix. Urban Ecosystems. Duluth, vol. 7, n. 3, p. 199-213, 2004.

GRIMM, N. B. et al. Global Change and the ecology of cities. Csience. n. 319 (5.864), p. 756-760, 2008.

HAUGHTON, G. Developing sustainable urban develoment model. Cities, n. 14, p. 189-195, 1997.

INTER-AMERICAM DEVELPMENT BANK (IDB). Good practies for urban greening. Washington: Environmental Division of Social Programs Sustainable Developement Departamento, 1997.

INSTITUTO DE PESQUISA ECONÔMICA APLICADA (Ipea). Comunicados do Ipea, $n^{\circ}$ 68: análise preliminar dos dados do Censo 2010. Brasília: IBGE, 2011.

IWAMA, A. Y. Indicador de arborização urbana como apoio ao planejamento de cidades brasileiras. Revista da Sociedade Brasileira de Arborização Urbana, Piracicaba, SP, v. 9, n. 3, p. 156-172, 2014.

LAGO, W. J. S. Determinação do índice de qualidade de vida urbana na área da Lagoa da Jansen e adjacências. 2001. Dissertação (Mestrado em Saúde e Meio Ambiente) Universidade Federal do Maranhão, 2001.

LIU, Z. et al. How much of the world's land has been urbanized, really? A hierarchical framework for avoiding confusion. Landscape Ecology, 29(5), p. 763-771, 2014.

LUCON, T. N.; PRADO FILHO, J. F.; SOBREIRA, F. G. Índice e percentual de áreas verdes para o perímetro urbano de Ouro Preto - MG. Revista da Sociedade Brasileira de Arborização Urbana, Piracicaba, v. 8, n. 3, p. 63-78, 2013.

LUZ, L. M.; RODRIGUES, J. E. C. Atlas de áreas verdes da cidade de Belém. Belém: Gapta; Ufpa, 2012.

MCDONNELL, M. J.; MACGREGOR-FORS, I. The ecological future of cities. Science, v. 352, n. 6.288, p. 936-938, 2016. 
MCINTYRE, N. E. et al. Ground arthropod community structure in a heterogeneous urban environment. Landscape and urban Planning, n. 52, p. 257-274, 2008.

MENDES, F. H et al. Estimativa do índice de área foliar para diferentes espécies arbóreas urbanas. Congresso Brasileiro de Arborização Urbana, 18., Rio de Janeiro, 2014.

MOURA, T. A.; SANTOS, V. L. V. Levantamento quali-quantitativo de espécies arbóreas e arbustivas na arborização viária urbana nos bairros Centro e Centro Norte, Várzea Grande, Mato Grosso, Brasil. Revista da Sociedade Brasileira de Arborização Urbana, v. 1, n. 1, p. 17-117, 2009.

NEGRI, S. M. O processo de segregação sócio espacial no contexto do desenvolvimento econômico da cidade de Rondonópolis - MT. 2008. Tese (Doutorado em Geografia) Unesp, Rio Claro, 2008.

NETTO, M. P.; SILVA, R. S. Ecossistemas urbanos: potencialidades da ecologia urbana no desenvolvimento de cidades sustentáveis. Encontro da Sociedade Brasileira de Economia Ecológica, 9., Brasília. 2011

NUCCI, J. C. Qualidade ambiental e adensamento urbano: um estudo de ecologia e planejamento da paisagem aplicado ao distrito de Santa Cecília (MSP). 2. ed. Curitiba: Ed. Humanitas, 2008.

NUCCI, J. C.; CAVALHEIRO, F. Cobertura vegetal em áreas urbanas: conceito e método. Geousp, São Paulo, n. 6, p. 29-36, 1999.

ODUM, E. Fundamentos da ecologia. 6. ed. Lisboa, Portugal: Fundação Calouste Gulbenkian, 1996.

OLIVEIRA, S. M. L.; NASCIMENTO, F. A. S. Ecologia e história do Vale do São Lourenço. Rondonópolis: Ed. da UFMT, 2004. 54p.

ORGANIZAÇÃO DAS NAÇÕES UNIDAS (ONU). Relatório sobre a população mundial 2014. Fundo de População das Nações Unidas - Unfpa. 2014.

PEREIRA, E. S. Expansão urbana e impactos ambientais no perímetro urbano de Rondonópolis - MT: uma comparação da situação da cobertura vegetal e das áreas de proteção ambiental nos anos de 1986 e 2008. 2009. Monografia (Especialização em Educação Ambiental) - Universidade Federal de Mato Grosso, 2009.

RAHMAN, D. M. A.; ARMSON, A. R.; ENNOS, A. Comparison of the growth and cooling effectiveness of five commonly planted urban tree species. Urban Ecosyst, New York, p. 371-389, 2014.

ROHLING, F. J.; SILVA, N. M. Padrão de fragmentação da vegetação nativa na zona rural associada ao perímetro urbano de Rondonópolis, Mato Grosso. Caminhos de Geografia, Uberlândia, v. 13, n. 41, p. 42-51, 2012. 
ROSSET, F. Procedimentos metodológicos para estimativa de indice de área verde pública. Estudo de Caso: Erechim - RS. 2005. Dissertação (Mestrado em Ecologia e Recursos Naturais) - Universidade Federal de São Carlos, São Carlos, 2005.

ROTHER, E. T. Revisão sistemática X revisão narrativa. Acta Paulista de Enfermagem, vol. 20, n. 2, p. 5-6, abr./jun. 2007.

SANTAMOUR JUNIOR, F. S. Trees for urban planting. Diversity uniformty, and common sense. U. S. National Abertum, Agriculture Reserch Service. U.S. Department of Agriculture Washington, D.C., 2002.

SECRETARIAT OF THE CONVENTION ON BIOLOGICAL DIVERSITY. Cities and Biodiversity Outlook. Montreal. 2012. Disponível em: <https://www.cbd. int/doc/health/cbo-action-policy-en.pdf $>$.

SETTE, Denise Maria. O clima urbano de Rondonópolis. 1996. Dissertação (Mestrado em Geografia) - Universidade de São Paulo, São Paulo, 1996.

SOCIEDADE BRASILEIRA DE ARBORIZAÇÃO URBANA - Sbau. Carta a Londrina e Ibiporã. Boletim Informativo, v. 3, n. 5, p. 3, 1996.

TERRADAS, J. Ecología Urbana. Barcelona: Rubes Editorial, 2001.

TIAN, Y. et al. Landscape ecological assessment of green space fragmentation in Hong Kong. Urban Forestry \& Urban Greening, Elsevier GmbH, v. 10, p. 79-86, 2011.

TOLEDO, F. S.; MAZZEI, K.; SANTOS, D. G. Um índice de áreas verdes (IAV) na cidade de Uberlândia/MG. Revista da Sociedade Brasileira de Arborização Urbana, v. 4, n. 3, p. 86-97, 2009.

WEAVER, W.; SHANNON, C. E. The mathematical theory of communication. Urbana, Ilinois: University of Ilinois, 1949.

WILLIAMS, J. N. Humans and biodiversity: population and demographic trends in the hotspots. Population and Environment, 34(4), p. 510-523, 2013.

ZANIN, E. M. Caracteriæação ambiental da paisagem urbana de Erechim e do Parque Municipal Longines Malinowski, Erechim - RS. 2002. Tese (Doutorado em Ecologia e Recursos Naturais) - Universidade Federal de São Carlos, Centro de Ciências Biológicas e da saúde, 2002.

Recebido em: 25/3/2016

Aceito em: 2/9/2016 